\title{
Mental Health Help-Seeking Behaviors of Muslim Immigrants in the United States: Overcoming Social Stigma and Cultural Mistrust
}

\author{
Saara Amri \\ Fred Bemak
}

George Mason University

Correspondence concerning this article should be addressed to: Saara Amri, George Mason University, Graduate School of Education, 4400 University Drive MS4F3, Fairfax, VA 22030, E-mail: Samri@masonlive.gmu.edu.

\section{Abstract}

As in many cultures and religions, the stigma of mental illness and treatment in the Muslim immigrant community is deep-rooted. Compounded with the cultural mistrust of the Western mental health system, many in this community live with untreated mental health conditions that not only impact themselves, but impact their family and the larger community. This article examines the Muslim immigrant community in the U.S. by providing an overview of who Muslim immigrants are and some of major psychosocial and psychological issues they face. The article will examine the impact of cultural mistrust and the stigmatization related to mental health on help-seeking behaviors among Muslim immigrants. Two case studies are presented that portray some of the struggles a Muslim immigrant faces in the U.S. Based on these case studies, recommendations for providing culturally responsive services that may mediate barriers to mental health help-seeking behaviors are presented. Finally, the authors discuss implications for future research.

Keywords: Muslim mental health, stigma, help-seeking behaviors, cultural mistrust, immigrant, culturally responsive services

There are approximately 7 million Muslims living in the U.S. (CAIR, 2010). A sizable portion of this population immigrated to the U.S. or are children 
of immigrants, with reasons for their immigration varying from education to escaping political persecution. Muslim immigrants in the U.S., because of their diverse cultural and ethnic backgrounds, and similar to other immigrant minority groups, face challenges such as marginalization, discrimination, racism, and struggles with acculturation (Ahmed \& Reddy, 2007). These challenges contribute to mental health difficulties, yet there is an underutilization of mental health services by Muslim immigrants (Aloud \& Rathur, 2009). Although little research has been conducted on the help-seeking behaviors of Muslim immigrants, reasons for the underutilization of services relate to the stigma of mental health in the Muslim culture and the cultural mistrust of mental health counselors and the mental health system (Al-Adawi et al., 2002; Sarfraz $\&$ Castle, 2002).

\section{The Muslim Immigrant - An Overview}

Muslim immigrants are those who were born in another country and immigrated to the U.S. or are the children of Muslim immigrants.. Both Muslim immigrants and children of immigrants share similar experiences being in the U.S., which is somewhat different than American-born convert Muslims or second- and third-generation children of immigrants. Muslim immigrants make up only a portion of the total Muslim population in the United States. Estimates of the total number of Muslims in the U.S. range anywhere from 2 million to 7 million, depending on the source and the method of data collection (Ali, Milstein, \& Marzuk, 2005; Ghaffari \& Ciftci, 2010; Hodge, 2002; Pew Research Center, 2007). The absence of a clearly agreed upon number of Muslim immigrants may relate to a hesitation to participate in surveys or provide information pertaining to their religion and/or ethnic background for fear of being targeted or discriminated against, which has been especially true post9/11. In addition, surveys and research on the Muslim immigrant population have yet to approach this population in a culturally responsive manner, taking into consideration cultural context and language barriers. An example such as the Pew Research Center offers an illustration of a research organization that has made strides in culturally responsive surveys.

According to a survey conducted by the Pew Research Center in 2007, approximately $65 \%$ to $75 \%$ of Muslims in the U.S. are immigrants, originating from 80 different countries around the world (CAIR, 2006; Hodge, 2002; Project MAPS, 2004). Among native U.S. born Muslims, approximately half are children of immigrants. The majority of Muslim immigrants in the U.S. originate from the Middle East and North Africa. South Asians (Afghanistan, Pakistan, India, Bangladesh, and Iran) represent the next largest group. Muslims in the U.S. have also immigrated from East and South East Asia, Africa, 
South and Central America, and Europe (Pew Research Center, 2007 \& 2011). AAlthough Muslim immigrants are widely spread across the U.S., most choose to immigrate to larger metropolitan areas such as New York City, Los Angeles, Detroit, Chicago, Washington, D.C., Atlanta, Houston, and St. Paul (CAIR, 2006; Duran \& Pipes, 2002).

As mentioned earlier, Muslims immigrate to the U.S. for various reasons. Those reasons include persecution based on ethnicity, religious beliefs/practices, and civil war and international conflict. Muslims may also immigrate to the U.S. in search of economic and educational opportunities, or to reunite with family or join a growing ethnic group (Ahmed \& Reddy, 2007; Duran \& Pipes, 2002).

Diversity among Muslim immigrants in the U.S. is also found in how the religion is observed. The Pew study looked at identity and found that approximately half of the Muslim immigrant population and their children in the U.S. identify as Sunni Muslim, with 22 percent not identifying with a particular sect, and 16 percent identifying as Shi'a Muslim. Not only do Muslim immigrants vary in religious affiliation, but they also vary in the way they practice and observe their religion (Duran \& Pipes, 2002; Pew Research Center, 2007).

\section{The Psychosocial Issues and Needs of Muslim Immigrants Issues}

Muslim immigrants come from diverse cultures and traditions which contribute a richness to U.S. society and culture. This diversity can also present many challenges for the Muslim immigrant and their families. Two main challenges experienced by this population are difficulty with acculturation and adjustment to their new life and discrimination and marginalization in society (AbuRas \& Suarez, 2009).

Most Muslim immigrants settled in the U.S. in the past 15 to 20 years (Pew Research Center, 2007). The process of acculturation can take two forms, either adoption and immersion of the dominant society, or immersion and retention of the ethnic society of origin (Awad, 2010; Berry, 2003); acculturation also depends on factors such as country of origin, sociopolitical history, reason for immigration, length of time in the U.S., socioeconomic status in the U.S., level of education and English language proficiency, level of social support, pre-migration experiences such as trauma, and post-migration experiences of trauma and racial/ethnic discrimination (Chung, Bemak, Ortiz, \& SandovalPerez, 2008; Erikson \& Al-Tamimi, 2001; Jamil, Nassar-McMillan, \& Lambert, 2007).

The dynamic between ethnic identity, religious identity, and American identity can be difficult to manage and can have a profound influence on the 
family system (CAIR, 2006; Hodge, 2002). As with most individuals who immigrate to the U.S., there is often a change in family roles which can be quite disruptive. Children are "parentified" because they tend to learn English much quicker than their parents and are put in positions to speak on their parent's behalf, or sometimes being required to make critical decisions that impact the family. Women are also often forced to take on the role of secondary, and sometimes, primary wage earners, leading to the male head of household feeling a loss of control and inadequacy (Ahmed \& Reddy, 2007; Awad, 2010; Bemak, Chung, \& Pedersen, 2003; Trickett \& Jones, 2007). Difficulty learning the English language and limited or non-transferrable job skills also present challenges for Muslim immigrants who are trying to start a new life in the U.S. They are unable to navigate the often-daunting social services system, educational system, legal system, and work force. The loss of status in society, an inability to provide for one's family, and unattained educational goals can lead to isolation and marginalization (Ahmed \& Reddy, 2007; Ali, Liu, \& Humedian, 2004).

In addition to difficulty adjusting and acculturating to life in the U.S., since the terrorist attacks of September 11, 2001, Muslim immigrants have faced significant discrimination and racial profiling (Ghaffari \& Ciftci, 2010). Legislation such as the Patriot Act and travel restrictions have made Muslim immigrants vulnerable to unfair targeting, including home raids, unjustified arrests and detentions, and interrogation (Ahmed \& Reddy, 2007; Amri, Nassar-McMillian, Meisenhimer, \& Bryan, in press; CAIR, 2002). The negative portrayal of Muslims and Islam in the media has only exacerbated this discrimination and racial profiling (Kira, et al., 2010; Padela \& Heisler, 2010). Right-wing media figures have smeared the image of Muslims and Islam and make no apologies for their Islamophobic views and beliefs.

In a study conducted by Hasouneh and Kulwicki (2007) that looked at discrimination, trauma, and mental health among Arab Muslim women in the U.S., the authors found that $63 \%$ of respondents reported being discriminated against post-9/11. While this study looked only at Arab women, Arab and Muslim men share similar experiences of discrimination (Abu-Ras \& Suarez, 2009). Muslim immigrants have also experienced discrimination in the workplace through denial of employment or wrongful firing, in the schools through denial of religious accommodations, and in public facilities (Ali, Liu, \& Humedian, 2004). In a study conducted by Zine (2001), the author explored the experiences of Muslim youth in a Canadian public school. Over the course of six months, the author interviewed 8 Muslim youth and 5 parents and found that the experiences of peer pressure, Islamophobia, racism, and social pressures were common. The youth reported being marginalized and discriminated against based on the clothing they wore (religious clothing) and the values and practices they observed. While this study was conducted in Canada, it is 
more than likely these experiences are shared by Muslim youth in the U.S. as well (Ahmed, 2009; Ahmed \& Ezzeddine, 2009).

\section{Mental Health Service Needs}

It is important to consider what services would be most beneficial to address the psychological needs of Muslim immigrants. Services must account for the diverse languages, cultures, traditions, and religious beliefs within the Muslim immigrant community. It is essential that mental health services are culturally responsive given the risk that ineffective responses can lead to a further isolation and marginalization of this growing minority group.

\section{Adolescent and Youth-Centered Services}

There is ongoing debate about the role of adolescents in immigrant families and the impact that role has on adolescent development (Leidy, Guerra \& Toro, 2010; Trickett \& Jones, 2007). Adolescent children of immigrants often find themselves in positions where they take on nontraditional roles in the family that can result in a shift in the power between the parent and the child. Muslim immigrant children face additional challenges. Hodge (2002) studied the importance of culturally appropriate interventions when working with Muslim youth in a social-work capacity, and discussed the profound impact of peer pressure to conform to popular norms on Muslim youth and the struggles they experience in reconciling that pressure with their religious and cultural values. Ahmed (2009) emphasizes the Muslim parent's role in helping Muslim youth navigate the challenges of living in the United States. With limited support from parents, Muslim youth often become confused, isolated, and experience a lack of acceptance. Barazinji (1993) presented a compelling case study of a child who, when faced with choosing between her family's values and mainstream culture, finds herself in conflict with her parents and her community. The child chooses to align herself with the dominant culture and Barazinji discusses the importance of the parents' role in helping children mediate that struggle and choice.

Peer pressure, racism, and discrimination, and social pressure to conform to mainstream values can put a Muslim child in a vulnerable position where they are apt to experience psychological issues such as anxiety and depression (Haque, 2004). For this reason, it is important to provide culturally responsive services to Muslim immigrant adolescents that take into consideration the child's mental health needs in relation to their cultural, family, and social contexts. 


\section{Parent and Family-Centered Services}

As important as addressing the needs of Muslim immigrant adolescents, is addressing the needs of Muslim immigrant parents and families. Positive parenting and family cohesion ultimately lead to positive adolescent development (Ali, Liu, \& Humedian, 2004; Leidy, Guerra, \& Toro, 2010). Having services that target the needs of parents is integral in building a healthy family system (Trickett \& Jones, 2007). Muslim immigrant parents may struggle with parenting their children. Having relied on extended family for parenting support, once in the U.S., Muslim immigrant parents struggle to take on the entire role by themselves, trying to negotiate between successful parenting skills, issues of discipline, and the possibly different values of household management and free expression. Parents may also struggle with marital conflict that can stem from the pressures of immigration and acculturation, parenting styles, and changing gender roles (Ahmed \& Reddy, 2007; Bemak, Chung, \& Pedersen, 2003).

Because Muslim immigrants come from collectivistic cultures (Ali, Liu, \& Humedian, 2004), it is important to consider that the individual may not see family concerns as only impacting themselves, but also having an effect on the larger family system. This coincides with mental health issues possibly stemming from larger family issues, thus making it that more important to consider the larger family system in treatment interventions. This may include family therapy or involving individual family members in the one-on-one counseling process (Erikson \& Al-Tamimi, 2001; Nassar-McMillan, 2008; Nobles \& Sciarra, 2000).

\section{Domestic Violence}

An issue that has not been discussed thoroughly is domestic violence and spousal abuse among the Muslim immigrant population. Issues that are becoming more prevalent, family violence and violence against women are rarely addressed due to cultural stigmas and beliefs that domestic violence is an appropriate form of discipline (Nacef, Belhadj, Bouasker, \& Ghachem, 2003). Patterns of abuse among Muslim immigrants are similar to those in the U.S. culture in that women often struggle to leave the abusive partner. However, the factors motivating that decision differ between the U.S. and Muslim immigrant cultures. Women in Muslim immigrant cultures believe that they must stay in abusive relationships to preserve the family, because it is their duty, or because they see few options outside of marriage as far as being able to support themselves financially and being isolated from their community (Gharaibeh \& Oweis, 2009; Haj-Yahia, 2000). 


\section{Substance Abuse}

The pressures of acculturation and adjustment among immigrant communities have been associated with an increase in substance use. However, little research has been done that looks at substance use and alcoholism in the Muslim immigrant communities (Ali, Liu, \& Humedian, 2004; Arfken, Berry, Owens, 2009). Alcohol and substance use are prohibited in Islam, however, that is not to say that Muslim immigrants do not use or abuse alcohol or drugs. While experimentation with alcohol and drugs may occur among Muslim immigrant youth who attend large universities or public schools, alcohol and drug use may also be used as a coping mechanism for struggles with PTSD, anxiety, and depression (Amri, Nassar-McMillian, Meisenhimer, \& Bryan, in press; NasserMacMillian \& Hakim-Larson, 2003). As in other cultures, the abuse of alcohol and drugs can lead to family conflict and domestic violence and, for this reason, it is absolutely crucial that there are substance abuse treatment services available to Muslim immigrants that take into consideration the individual's cultural and religious contexts (Arfken, Kubiak, \& Farrag, 2007).

\section{Trauma Treatment}

Given the circumstances under which refugees flee their countries, they are often faced with significant challenges once they are resettled. Enduring community violence, political torture, and the loss of their homes, livelihood, family and loved ones, refugees often suffer from depression, anxiety, and PTSD (Daud, Klinteberg, \& Rydelius, 2008; Jamil et al., 2002). These mental health issues are often compounded with the challenges of acculturation and adjustment to their new life, which alone can be quite daunting to overcome (Bemak, Chung, \& Pedersen, 2003; Jamil, Nassar-McMillan, \& Lambert, 2007; Amri, Nassar-McMillian, Misenheimer, \& Bryan, in press), as well as the added trauma of discrimination and racism, and the daily confrontation of Islamophobia (Inayat, 2007). Mental health services that address pre-migration and postmigration trauma are essential in working with the Muslim immigrant population. If not resolved appropriately, these traumas can have a severe impact on the individual's ability to function normally, to be able to maintain gainful employment, learn English, parent children, be supportive partners, and be productive members of their communities (Hepinstal, Stethna, \& Taylor, 2004).

\section{Social Stigma and Cultural Mistrust}

Social stigma and cultural mistrust are constant challenges to accessing mental health services for immigrants and minorities (Aloud \& Rathur, 2009; Sarfraz 
\& Castle, 2002). Attitudes toward mental health help-seeking have been widely studied in minority and immigrant communities. Many who are in need of mental health services are reluctant to seek out these services for fear being stigmatized and outcast in their communities. Additionally, there is a lack of culturally competent mental health services available to minorities and immigrants, thus furthering the gap between mental health help-seeking and attitudes toward mental health services (Fischer \& Farina, 2005; Townes, ChavezKorell, \& Cunningham, 2009; Vogel, Wade, \& Hackler, 2007).

\section{The Social Stigma of Mental Health Problems and Help-Seeking}

In many cultures, there is a strong stigma that is attached to mental health and treatment of psychological conditions. The stigma not only attaches itself to the individual who is ill, it also attaches itself to the family (Aloud \& Rathur, 2009; Hsu \& Alden, 2008). The belief that mental problems are attributed to a lack of faith, spirit possession, bad karma, and the evil eye is strongly engrained in many non-Western cultures. This may encourage families and individuals to avoid seeking help for their psychological problems for fear that they will shame their family or that they are revealed as being weak. Some cultures also believe that admitting to having a mental health problem is a form of loss of face and shameful (Aloud \& Rathur, 2009; Cauce et al., 2002; Sarfraz \& Castle, 2002; Vogel, Wade, \& Hackler, 2007).

For Muslim immigrants, the social stigma that surrounds mental health problems is profound. This is particularly true since Islam is seen as the source for healing and strength, especially as it relates to mental health (Ali, Milstein, \& Marzuk, 2005; Ghaffari \& Ciftci, 2010). An individual with mental health problems is viewed as "crazy", someone who has lost their faith in God or has lost their way (Erikson \& El-Tamimi, 2001; Vogel, Wade, \& Hackler, 2007). Because of the stigma attached to psychological problems, many Muslim immigrants prefer to seek help from within their family or community, an approach that is more socially acceptable and protects the family from negative public opinion (Carolan et al., 2000; Ali, Milstein, \& Marzuk, 2005; Ali, Liu, \& Humedian, 2004; Al-Krenawi \& Graham, 2000). Muslim immigrant cultures also encourage individuals with mental health problems to "toughen up" and "deal" with struggles with depression and anxiety, or family conflict (Cauce et al., 2002). This is especially true for males who are expected to be strong and support their family (Vogel, Wade, \& Hackler, 2007). Women are less likely to internalize the stigma against seeking mental health services and are therefore more open to receiving mental health assistance. (Ali, Liu, \& Humedian, 2004; Farooqi, 2005; Haque, 2008; Vogel, Wade, \& Hackler, 2007). Because the 
stigma of mental health problems and help-seeking behavior is strong among Muslim immigrants, many go without essential treatment and often unnecessarily struggle with a mental health issue that could be easily resolved with professional help (Aloud \& Rathur, 2009; Redmond, Galea, \& Delva, 2009).

\section{Cultural Mistrust of Mental Health Counselors}

Minorities in the U.S. have historically experienced racism, discrimination, and oppression to the extent that these experiences have negatively influenced mental health help-seeking (Chung \& Bemak, 2012; Obasi \& Leong, 2009; Shea \& Yeh, 2008). Initially developed as a concept to describe the distrust Black Americans had towards White Americans, cultural mistrust encompasses an overall mistrust of White-dominated institutions such as the legal system, educational system, job settings, and government agencies (David, 2010). Many studies found that cultural mistrust resulted in a preference by Black clients for Black counselors, negative attitudes toward seeking psychological treatment, and a propensity to terminate therapy prematurely (Sue \& Sue, 1972; Townes, Chavez-Korell, \& Cunningham, 2009). These findings have been generalized to other minority groups including Southeast Asians and Latinos (David, 2010; Shea \& Yeh, 2008).

Cultural mistrust among Muslim immigrants is just as prevalent as in other minority groups, and is a significant barrier to mental health help-seeking. Because Muslim immigrants are encouraged to deal with their mental health issues internally (i.e., in their community and extended families), naturally, there is a mistrust toward mental health counselors in general (Ali, Liu, \& Humedian, 2004; Al-Krenawi \& Graham, 2000). However, this general mistrust is compounded by the mistrust of non-Muslim or American mental health professionals (Erickson \& El-Tamimi, 2001; Inayat, 2007). This is especially true for those who have experienced discrimination post-9/11 (Padela \& Heisler, 2010). Muslim immigrants may question the intentions of the counselor believing that non-Muslim and American mental health counselors lack an ability to understand the cultural and religious contexts in which they live, and subsequently may steer the individual in the wrong direction or encourage them to take action that may be in conflict with their values and belief systems (Ali, Liu, \& Humedian, 2004; Erickson \& Al-Tamimi, 2001; Inayat, 2007). As with the social stigma of mental health problems and help-seeking, cultural mistrust can have a profound impact on an individual's attitude toward seeking and receiving mental health treatment, furthering the prevalence of unmet mental health needs and the increase in social isolation and marginalization (Redmond, Galea, \& Delva, 2009). 


\section{The MPM}

Taking a culturally sensitive approach to mental health interventions with Muslim immigrants is crucial. The Multi-Phase Model of Psychotherapy, Social Justice and Human Rights (MPM) (Bemak \& Chung, 2008; Bemak, Chung, \& Pedersen, 2003; Chung \& Bemak, 2012) is one such approach that provides mental health counselors with tools to better serve the immigrant community, and, in this case, the Muslim immigrant population, and to address social stigma and cultural mistrust.

The MPM is an approach that holds at its core human rights, social justice, and multicultural counseling competencies (Chung, Bemak, Ortiz, \& Sandoval-Perez, 2008; Chung \& Bemak, 2012). It is an approach that focuses on the needs of immigrants, with the ultimate goal of developing a culturally responsive mental health intervention model that assists immigrants to better adapt and adjust to their post-migration lives. Through this approach, the mental health practitioner expands their traditional role and functions as a skilled multicultural mental health practitioner, social justice advocate, community engager networker, and consultant. The psychologist or counselor is expected to collaborate with others directly and indirectly involved in the immigrant client's life. This may include collaboration with family, friends, colleagues, local religious and community leaders, schools, law enforcement, and policy makers. The MPM also requires that the psychologist or counselor have a thorough knowledge of the immigrant client's socio-political history, past and present traumas, history of discrimination and racism, religious and spiritual beliefs, as well as the cultural beliefs around mental health and help-seeking (Chung, Bemak, Ortiz, Sandoval-Perez, 2008).

The MPM consists of five phases of intervention, all integral to the overall successful adaptation and acculturation of immigrants (Bemak \& Chung, 2008). Each phase plays a significant role in the treatment process.

\section{Phase 1: Mental Health Education}

Psychoeducation is a priority when providing mental health services to the immigrant population. The majority of Muslim immigrants come from countries where mental health services are reserved for the severely mentally ill, and often involve institutionalization. Therefore, it is important to be able to explain to immigrant clients what is involved in that counseling process and the role of the mental health counselor (Al-Adawi et al., 2002). It is also important to explain and clarify stigmas and misconceptions about mental health and mental illness. Phase 1 of the MPM educates the client at the beginning of the therapeutic relationship, introducing to the client what actually happens in 
counseling, discussing the benefits of counseling and dispelling the social and cultural myths of mental health.

Phase 2: Individual, Group, and Family Interventions

Mental health services must be provided in a culturally responsive manner, taking into consideration the cultural, religious, historical, and social contexts of the immigrant client. Psychologists and counselors must be aware of critical related issues such as language needs, gender roles, family hierarchy, family history, and spiritual practices. For example, for many immigrants, group interventions tend to be problematic since family privacy and discretion are valued traits. This is especially true in Muslim immigrant cultures, leading to less inclination to participate (Nassar-McMillan \& Hakim-Larson, 2003). Paying attention to gender roles (e.g., pairing a female client with a male counselor) and family hierarchy (e.g., undermining a dominant father when providing a family intervention involving children), as mentioned above, is important when considering which intervention is more appropriate for the Muslim immigrant client.

\section{Phase 3: Cultural Empowerment}

In working with immigrant clients, is important to provide them with cultural orientation and the tools to navigate barriers such as using public transportation, applying for employment, accessing public benefits, or knowing where to go for language training. This means that the counselor becomes an advocate for and with the client. Since mastering the culture is critical for immigrants, this is a key aspect of the MPM and helps the client bridge the social and technical knowledge gap.

\section{Phase 4: Integration of Traditional and Western Healing Practices}

Phase 4 is extremely important when working with Muslims who have migrated, especially given possible strong religious and cultural context of Muslim immigrants. Muslim immigrants are more likely to look to their religion for healing (Abu-Ras \& Suarez, 2009; Aloud \& Rathur, 2009). It is critical for the psychologist or counselor to be able to give the client the option of integrating religious and traditional healing practices into the therapeutic process. This may involve the counselor collaborating directly with local religious or traditional healers and acquiring knowledge about traditional healing practices common in the immigrant client's culture (Bemak, Chung, \& Pedersen, 2003; Erikson \& Al-Tamimi, 2001; Nobles \& Sciarra, 2000). 


\section{Phase 5: Addressing Social Justice and Human Rights Issues}

Phase 5 involves addressing social injustices and human rights violations in the therapeutic relationship. Not only does the counselor serve as the advocate, connecting the client to resources and services they otherwise may not have access to, but also helps the client learn how to advocate for themselves against social injustices or lack of access to resources and services in the community. In Phase 5, the psychologist or counselor encourages the client to join community groups that are acting on a community level to advocate for social justice issues in the Muslim immigrant community (Ratts \& Hutchins, 2009; Toporek, Lewis, \& Crethar, 2009).

Below are case studies that provide a snapshot of two Muslim immigrant men, the mental health issues they are struggling with, and how social stigma and cultural mistrust interfere with seeking help. The MPM will be presented as a model of intervention that can be used to mitigate the barriers these two clients are experiencing in seeking mental health services.

\section{Case Studies}

\section{Ahmed}

Ahmed is a 48-year-old Afghan refugee who resettled in the U.S. with his wife and three children, ages 24, 18, and 14. Before coming to the U.S., Ahmed was a commissioner in the Afghan police force. He made a good living and was able to live a comfortable life and provide for his family's needs. In Afghanistan, Ahmed's wife did not need to work and instead, was expected take care of her of children and the household. Ahmed and his family fled to Pakistan after receiving death threats by unknown individuals warning him to stop working with the "Americans". Once resettled to the U. S., Ahmed found his life to be more difficult than he imagined. With limited English language skills, he was unable to find employment as soon as he had hoped. He also found it difficult to cover his household expenses with the little assistance provided by social services and the federal government. His wife and adult children also faced the same struggle with limited-to-no English language skills and no transferrable job skills.

Six months after arrival in the U.S., the tension in Ahmed's household began to increase. He was no longer able to communicate with his wife without getting into arguments. Ahmed's anger and resentment began to increase, as did his anxiety and depression. He would often lock himself in his closet to cry and would have frequent panic attacks. Ahmed's case manager encouraged him to seek counseling, but Ahmed refused, stating that he was not crazy. He also 
did not want his family to know that he needed help. One evening, Ahmed's anger reached the point where he lashed out against his wife, shoving her against the wall after she made a comment about his lack of employment. Ahmed's youngest child called the police who arrested Ahmed and ordered that he stay away from the home for 72 hours - he slept in his car for the next several nights. Ahmed was ordered to attend anger management classes through the local county mental health center. The classes were only offered in English and Spanish and cost $\$ 25$ a meeting.

Ahmed's individually and socially imposed stigma is apparent. He struggles with a loss of face, feeling disempowered and humiliated. He is no longer able to be the main breadwinner and Ahmed is unable to cope with this change in role. In Ahmed's eyes, the fact that he cannot find work and support his family in the "land of opportunity" is a huge disappointment, which is further compounded by his arrest. Cultural mistrust plays a significant role in preventing Ahmed from reaching out for help. Ahmed has little faith in the U.S. system and, compounded with his own beliefs about mental health, he has even less faith in the mental health system.

For Ahmed, participating in group anger management sessions would be highly uncomfortable given his cultural values of personal pride and discretion. Thus Ahmed would be reluctant, even if he were more proficient in English, to share his personal experiences with a group of strangers. In looking at the MPM as an approach to working with Ahmed, education would be key to helping Ahmed understand the benefits of anger management. Additionally, a more appropriate intervention to address anger management would be to refer Ahmed to a male Farsi-speaking individual counselor who could provide Ahmed with the support needed through an approach that is more culturally responsive and acceptable. Matching the client with a linguistically and culturally similar provider is integral in improving access to services (Aloud \& Rathur, 2009). Ahmed also needs orientation to the U.S. system and needs to understand how to navigate that system in an effort to avoid such issues in the future. Finally, it is worth exploring with Ahmed his experiences of marginalization and discrimination, as these are likely contributors to his struggles.

\section{Majeed}

Majeed is a 62 year-old Algerian father of two. He immigrated on his own to the United States 30 years ago in search of better job opportunities. A year after arriving to the U.S., he met his wife, a Christian White American. Majeed's wife converted to Islam soon after they married. Majeed and his wife had a successful life, earning a good living while raising two children. Majeed wanted both his children to have a strong command of their faith and the Arabic language and decided to send them to a private Islamic school. Majeed also traveled with 
his family to Algeria every summer to ensure that the children were familiar with their culture and traditions.

Majeed worked in the food service industry. Throughout his career, Majeed experienced daily discrimination, being one of the few minorities and the only Arab in upper management. This discrimination increased post-9/11. Majeed felt a lack of safety and trust toward Americans, especially White Americans. After visits to his home by the FBI and continuous harassment at airports, Majeed's faith in living freely and peacefully in the U.S. diminished. Majeed began to notice that his employer was hiring employees in the same job grade with salaries $40 \%$ higher than his own. These new employees were less experienced, young White men. When his employer lost a major contract, Majeed was told that there were no other equivalent positions in other contracts to which he could be transferred and therefore, Majeed was let go. Soon after, Majeed found out that his White, younger counterparts were all re-hired in equivalent or higher positions.

Majeed was forced to file for unemployment. His wife, now the only income earner in the home, was forced to work 14-hour days to cover their monthly expenses. This change was devastating to Majeed and caused him to spiral into a deep depression. He lost interest in the things he normally enjoyed doing, he became irritable and often lashed out at his wife and children for seemingly simple issues. He spent most of his days in bed watching TV and took little part in daily activities with his family. Majeed's family felt helpless because they knew there was no way he would seek mental health support because of the strong social stigma.

Similar to Ahmed, Majeed is struggling with a loss of face and a change of role within the family. However, Majeed was once successful and has lived in the U.S. for several decades. He is adjusted to life in the U.S. and maneuvered successfully between his culture of origin and American culture. This all changed post-9/11. Majeed lost faith in Americans and, even though he was struggling emotionally, Majeed associated the mental health system with Americans. $\mathrm{He}$ believed that mental health services were run by White Americans and had little trust in their ability to understand his experiences of discrimination and, similar to Ahmed, believed that mental health professionals wouldn't understand his culture and the related social stigma of seeing a counselor. The MPM is an ideal model to use in working with Majeed because it focuses on human rights and social justice issues and helps the client to learn how to be an advocate for him or herself. With Majeed, the counselor needs to spend time processing and exploring Majeed's experiences of discrimination and his disillusionment within the U.S., and redefine his experience in counseling in order to make it palatable to the Muslim community. This is critical in helping him move past the trauma of losing his livelihood and status in his family and community. He also needs tools to help him advocate for his rights. For example, 
Majeed could explore consulting with the Equal Employment Opportunity Commission to see if he has grounds to file a claim against his employer.

\section{Community-Based Services and Community Engagement}

Although offering and providing culturally responsive services to Muslim immigrants is integral to meeting the mental health needs of this population, it still does not completely solve the issue of cultural mistrust and the stigma of mental health. In addition to these services, mental health providers must consider nontraditional therapeutic interventions to reach the Muslim immigrant community on their turf where they may be more comfortable (Al-Krenawi \& Graham, 2000; Aloud \& Rathur, 2009). Simultaneously, providers can solicit the cooperation of the Muslim immigrant community in assessing and addressing the mental health needs of their members (Cauce et al., 2002; Chung, Bemak, Ortiz, \& Sandoval-Perez, 2008; Nassar-McMillan \& Hakim-Larson, 2003).

It is not realistic to expect Muslim immigrants to seek out mental health services in mental health clinics which may appear intimidate or uninviting. Services offered in the community at the local mosque, school, or neighborhood community center may diminish the stigma attached to mental health, and provide easy access of services in a familiar and safe environment. Mental health interventions can also be co-constructed by community and religious leaders in an effort to combine traditional and cultural practices with Western clinical practice. Similar to the MPM's third phase, cultural empowerment, positive mental health is directly associated with a feeling of confidence and mastery of the mainstream cultural system (Bemak, 1989). For example one intervention that can be used in the community setting is teaching English while incorporating mental health tools, whereby the client is learning English while at the same time learning about mental health and symptoms such as anxiety, depression, family conflict, etc.

Furthermore, it is important to solicit the input and support of the Muslim immigrant community as it relates to addressing mental health issues and encourage the community to develop their own interventions and support systems as a means of increasing access to much-needed information and help (Reitmanova \& Gustafson, 2008). For example, in the case of Ahmed, it may have helped to approach the Muslim immigrant community; a counselor might consult with the local mosque, to set up a domestic violence and anger management discussion group for Muslim men. The group could be held at the local mosque, an environment that would be much less threatening than the county mental health center, and discuss domestic violence and couples communication through a spiritual and cultural lens. The group could be cofacilitated by a religious leader or Imam, and a male mental health counselor. 
Similar groups for Muslim men and women who have faced discrimination in the workplace or in another setting would also be examples of the types of interventions that could be helpful on a community level, and, in the case of Majeed, might have been valuable.

Kira, Ahmed, Mahmoud and Wassim (2010) developed a communitybased group intervention for Somali, Ethiopian and other sub-Saharan women survivors of Female Genital Circumcision, the Bashaal Group. The Bashaal Group was initially a group designed to increase group cohesion, develop social advocacy skills, and promote individual and group healing among the women, but evolved into a social club for women that continued to meet and gather long after the group intervention had ended. The women were encouraged to develop their own form of healing and support that incorporated their own cultural values and traditions. They met at a local community center near the community's mosque in a meeting room designed by the women survivors to resemble a typical social gathering setting in their home countries; meetings were facilitated by counselors, case managers and women community leaders/ liaisons, and interpreters.

\section{Implications for Future Research}

In order to begin to shift the focus of mental health services from the agency setting to the community setting, it is important to begin with understanding what the community's needs are and how it believes the needs can be met. This can take the shape of town hall meetings to discuss a specific issue or smaller focus groups where more in-depth qualitative data can be collected. It would also be worth exploring what Muslim immigrants' thoughts are about barriers to seeking mental health services and how those barriers can be overcome. Finally, interventions and programs aimed directly at Muslim immigrants need to be evidenced-based in order to develop alternative approaches to mental health treatment that can be successful and culturally responsive.

\section{Conclusion}

The Muslim immigrant community in the United States is vast in its diversity, representing multiple languages and cultural traditions. As diverse are the mental health struggles that many face on a daily basis, yet avoid seeking conventional treatment for. While there are few studies that have looked specifically at stigma and cultural mistrust among Muslim immigrants as it relates to mental health and help-seeking behaviors, a strong connection can be made that suggests that the stigma of mental health problems and treatment and the 
cultural mistrust of the mental health system are major barriers to Muslim immigrants seeking mental health treatment. Providing culturally responsive and sensitive services to this population is a first step to addressing these barriers. Theories such as the Theory of Reasoned Action (Ajzen \& Fishbein, 1980) and models of mental health help-seeking developed by Molock and colleagues (2007), Aloud and Rathur (2009), and Cauce and colleagues (2002) attempt to understand and address the role of social stigma and cultural mistrust in help-seeking behaviors of minorities; however, further research needs to be conducted to explore the opinions and thoughts of Muslim immigrants and the barriers they face in addressing their mental health needs. There are interventions that have been implemented in community-based settings that are promising, yet, in order to make a larger shift in the mental health field, interventions and studies need to be evidenced-based and need to demonstrate that they are successful in addressing and mediating the mental health issues faced by Muslim immigrants.

\section{References}

Abu-Ras, W. M., and Suarez, Z. E. (2009). Muslim men and women's perception of discrimination, hate crimes, and PTSD symptoms post 9/11. Traumatology, 15, 48-63. http://dx.doi.org/10.1177/1534765609342281

Ahmed, S. (2009). Religiosity and presence of character of strengths in American Muslim youth. Journal of Muslim Mental Health, 4, 104-123. http://dx.doi. org/10.1080/15564900903245642

Ahmed, S., \& Ezzedine, M. (2009). Challenges and opportunities facing American Muslim youth. Journal of Muslim Mental Health, 4, 159-174. http://dx.doi. org/10.1080/15564900903245782

Ahmed, S., \& Reddy, L. A. (2007). Understanding the mental health needs of American Muslims: Recommendations and considerations for practice. Journal of Multicultural Counseling and Development, 35, 207-218. http://dx.doi.org/10.1002/j.21611912.2007.tb00061.x

Ajzen, I., \& Fishbein, M. (1980). Understanding attitudes and predicting social behavior. Englewood Cliffs, NJ: Prentice-Hall.

Al-Adawi, S., Dorvlo, A., Al-Ismaily, S., Al-Ghafry, D., Al-Noobi, B., Al-Salmi, A., et al. (2002). Perception of and attitude toward mental illness in Oman. International Journal of Social Psychiatry, 48, 305-317. http://dx.doi. org/10.1177/002076402128783334

Ali, O., Milstein, G., \& Marzuk, P. (2005). The imam's role in meeting the counseling needs of Muslim communities in the United States. Psychiatric Services, 56, 202205. http://dx.doi.org/10.1176/appi.ps.56.2.202

Ali, S. R., Liu, W. M., \& Humedian, M. (2004). Islam 101: Understanding the religion and therapy implications. Professional Psychology: Research and Practice, 35, 635642. http://dx.doi.org/10.1037/0735-7028.35.6.635

Al-Krenawi, A., \& Graham J. R. (2000). Culturally sensitive social work practice with 
Arab clients in mental health settings. Health and Social Work, 25, 9-22. http:// dx.doi.org/10.1093/hsw/25.1.9

Aloud, N., \& Rathur, A. (2009). Mental health and psychological services among Arab Muslim populations. Journal of Muslim Mental Health, 4, 79-103. http://dx.doi. org/10.1080/15564900802487675

Amri, S. A., Nassar-McMillan, S. C., Meisenhimer, M., \& Bryan, S. A. (in press). Counseling Arab Americans. In C.C. Lee (Ed.). Counseling for diversity. (3rd ed., pp. 135-147). Alexandria, VA: American Counseling Association.

Arfken, C. L., Kubiak, S. P., \& Farrag, M. (2009). Acculturation and poly-substance abuse in Arab American treatment clients. Transcultural Psychiatry, 46, 608-622. http://dx.doi.org/10.1177/1363461509351364

Awad, G. H. (2010). The impact of acculturation and religious identification on perceived discrimination for Arab/Middle Eastern Americans. Cultural Diversity and Ethnic Minority Psychology, 16, 59-67. http://dx.doi.org/10.1037/a0016675

Barazanji, N. (1993). Particularism and multicultural education: Muslims' experience in the United States. Unpublished manuscript, Women's Studies Program, Cornell University, Ithaca, New York.

Bemak, F. (1989). Cross-cultural family therapy with Southeast Asian refugees. Journal of Strategic and Systemic Therapies, 8, 22-27.

Bemak, F., \& Chung, R. C.-Y. (2008). Counseling and psychotherapy with refugees. In P. B. Pedersen, J. G. Draguns, W. J. Lonner, \& J. E. Trimble (Eds.), Counseling across cultures (6th ed., pp. 307-324). Thousand Oaks, CA: Sage.

Bemak, F., Chung, R. C-Y., \& Pedersen, P. B. (2003). Counseling refugees: A psychosocial approach to innovative multicultural interventions. Westport, CT: Greenwood Press.

Berry, J. W. (2003). Conceptual approaches to acculturation. In K. M. Chun, P. Balls Organista, \& G. Martin, Acculturation: Advances in theory, measurement, and applied research (pp. 17-37). Washington, D.C.: American Psychological Association. http://dx.doi.org/10.1037/10472-004

CAIR. (2010). About Islam and American Muslims. Retrieved on September 1, 2010, from http://www.cair.com/AboutIslam/IslamBasics.aspx

CAIR. (2006). Western Muslim minorities: Integration and disenfranchisement. Retrieved on August 15, 2010, from http://www.cair.com/Portals/0/pdf/policy_bulletin_Integration_in_the_West.pdf.

Carolan, M. T., Bagherinia, G., Juhari, R., Himelright, J., \& Mouton-Sanders, M. (2002). Contemporary Muslim families: Research and practice. Contemporary Family Therapy, 22, 67-79. http://dx.doi.org/10.1023/A:1007770532624

Cauce, A. M., Domenech-Rodriguez, M., Paradise, M., Cochran, B. N., Shea, J. M., Srebnik, D., et al. (2002). Cultural and contextual influences in mental health helpseeking behavior: A focus on ethnic minority youth. Journal of Consulting and Clinical Psychology, 70, 44-55. http://dx.doi.org/10.1037/0022-006X.70.1.44

Chung, R. C-Y., \& Bemak, F. (2012). Social justice counseling: The next steps beyond multiculturalism. Thousand Oaks, CA: Sage.

Chung, R. C.-Y., Bemak, F., Ortiz, D., \& Sandoval-Perez, P. (2008). Promoting the mental health of immigrants: A multicultural/social justice perspective. Journal of Counseling and Development, 86, 310-317. http://dx.doi.org/10.1002/j.15566678.2008.tb00514.x

Daud, A., Klinteberg, B. A., \& Rydelius, P.-A. (2008). Trauma, PTSD, and personality: The relationship between prolonged traumatization and personality impairments. 
Scandinavian Journal of Caring Sciences, 22, 331-340. http://dx.doi.org/10.1111/ j.1471-6712.2007.00532.x

David, E. J. R. (2010). Cultural mistrust and mental health help-seeking attitudes among young Filipino Americans. Asian American Journal of Psychology, 1, 57-66. http://dx.doi.org/10.1037/a0018814

Douki, S., Nacef, F., Belhadj, A., Bouasker, A., \& Ghachem, R. (2003). Violence against women in Arab and Islamic countries. Archives of Women's Mental Health, 6, 165171. http://dx.doi.org/10.1007/s00737-003-0170-x

Erickson, C. D., \& Al-Tamimi, N. R. (2001). Providing mental health services to Arab Americans: Recommendations and considerations. Cultural Diversity and Ethnic Minority Psychology, 7, 308-327. http://dx.doi.org/10.1037/1099-9809.7.4.308

Farooqi, Y. N. (2006). Traditional healing practices sought by Muslim psychiatric patients in Lahore, Pakistan. International Journal of Disability, Development, and Education, 53, 401-415. http://dx.doi.org/10.1080/10349120601008530

Fischer, E. H., \& Farina, A. (1995). Attitudes toward seeking professional psychological help: A shortened form and considerations for research. Journal of College Student Development, 36, 368-373.

Ghaffari, A., \& Ciftci, A. (2010). Religiosity and self-esteem of Muslim immigrants to the United States: The moderating role of perceived discrimination. The International Journal for the Psychology of Religion, 20, 14-25. http://dx.doi. org/10.1080/10508610903418038

Gharaibeh, M. \& Oweis, A. (2009). Why do Jordanian women stay in an abusive relationship? Implications for health and social well-being. Journal of Nursing Scholarship, 41, 376-384. http://dx.doi.org/10.1111/j.1547-5069.2009.01305.x

Haj-Yahia, M. M. (2000). Wife abuse and battering in the sociocultural context of Arab society. Family Process, 39, 237-255. http://dx.doi.org/10.1111/j.1545-5300.2000.39207.x

Haque, A. (2004). Religion and mental health: The case of American Muslims. Journal of Religion and Health, 43, 45-58. http://dx.doi.org/10.1023/ B:JORH.0000009755.25256.71

Hassouneh, D. M., \& Kulwicki, A. (2007). Mental health, discrimination, and trauma in Arab Muslim women living in the U.S.: A pilot study. Mental Health, Religion, and Culture, 10, 257-262. http://dx.doi.org/10.1080/13694670600630556

Hodge, D. (2002). Working with Muslim youths: Understanding the values and beliefs of Islamic discourse. Children and Schools, 24, 6-20. http://dx.doi.org/10.1093/ $\mathrm{cs} / 24.1 .6$

Hsu, L., \& Alden, L. (2008). Cultural influences on willingness to seek treatment for social anxiety in Chinese and European-heritage students. Cultural Diversity and Ethnic Minority Psychology, 3, 215-223. http://dx.doi.org/10.1037/10999809.14.3.215

Inayat, Q. (2007). Islamophobia and therapeutic dialogue: Some reflections. Counseling Psychology Quarterly, 20, 287-293. http://dx.doi.org/10.1080/09515070701567804

Jamil, H., Hakim-Larson, J., Farrag, M., Khafaji, T., Duqum, I., \& Jamil, L. H. (2002). A retrospective study of Arab American mental health clients: Trauma and the Iraqi refugees. American Journal of Orthopsychiatry, 72, 355-361. http://dx.doi. org/10.1037/0002-9432.72.3.355

Jamil, H., Nassar-McMillan, S. C., \& Lambert, R. G. (2007). Immigration and attendant psychological sequalae: A comparison of three waves of Iraqi immigrants. Journal of Orthopsychiatry, 77, 199-205. http://dx.doi.org/10.1037/0002-9432.77.2.199 
Kira, I., Ahmed, A., Mahmoud, V., \& Wassim, F. (2010). Group therapy model for refugee and torture survivors. Torture, 20, 108-113.

Leidy, M. S., Guerra, N. G., \& Toro, L. I. (2010). Positive parenting, family cohesion, and child social competence among immigrant Latino families. Journal of Family Psychology, 24, 252-260. http://dx.doi.org/10.1037/a0019407

Lindencrona, F., Ekbauld, S., \& Hauff, E. (2008). Mental health of recently resettled refugees from the Middle East in Sweden: The impact of pre-resettlement trauma, resettlement stress, and capacity to handle stress. Social Psychiatry and Psychiatry Epidemiology, 43, 121-131. http://dx.doi.org/10.1007/s00127-007-0280-2

Molock, S. D., et al. (2007). Qualitative study of suicidality and help-seeking behaviors in African American adolescents. American Journal of Community Psychology, 40, 52-63. http://dx.doi.org/10.1007/s10464-007-9122-3

Nassar-McMillan, S., \& Hakim-Larson, J. (2003). Counseling considerations among Arab Americans. Journal of Counseling and Development, 81, 150-159. http:// dx.doi.org/10.1002/j.1556-6678.2003.tb00236.x

Nassar-McMillan, S. C. (2008). Arab Americans. In B. Erford (Ed.), American Counseling Association encyclopedia of counseling. Washington, D.C.: ACA.

Nobles, A. Y., \& Sciarra, D. T. (2000). Cultural determinants in treatment of Arab Americans: A primer for mainstream therapists. American Journal of Orthopsychiatry, 70, 182-191. http://dx.doi.org/10.1037/h0087734

Obasi, E. M., \& Leong, F. T. L. (2009). Psychological distress, acculturation, and mental health-seeking attitudes among people of African descent in the United States: A preliminary investigation. Journal of Counseling Psychology, 56, 227-238. http:// dx.doi.org/10.1037/a0014865

Padela, A. I., \& Heisler, M. (2010). The association of perceived abuse and discrimination after September 11, 2001 with psychological distress, level of happiness, and health status among Arab Americans. American Journal of Public Health, 100, 284291. http://dx.doi.org/10.2105/AJPH.2009.164954

Pew Research Center. (2007). Muslim Americans: Middle class and mostly mainstream. Retrieved on August 20, 2010, from http://pewresearch.org/assets/pdf/ muslim-americans.pdf.

Pew Research Center. (2011). Muslim Americans: No sign of growth in alienation or support for extremism. Retrieved on May 6, 2013, from http://www.peoplepress.org/2011/08/30/muslim-americans-no-signs-of-growth-in-alienation-orsupport-for-extremism/.

Pipes, D., \& Duran, K. (2002). Muslim immigrants in the United States. Center for Immigration Studies, retrieved on August 10, 2010, from http://www.cis.org/USMuslimImmigrants.

Project MAPS. (2004). Muslims in the American public square: Shifting political winds and fallout from 9/11, Afghanistan, and Iraq. Retrieved on May 6, 2013, from http://www.aclu.org/files/fbimappingfoia/20111110/ACLURM001733.pdf.

Ratts, M. J., \& Hutchins, M. A. (2009). ACA advocacy competencies: Social justice advocacy at the client/student level. Journal of Counseling and Development, 87, 269-275. http://dx.doi.org/10.1002/j.1556-6678.2009.tb00106.x

Redmond, M. L., Galea, S., \& Delva, J. (2009). Examining racial/ethnic minority treatment experiences with specialty behavioral health service providers. Community Mental Health Journal, 45, 85-96. http://dx.doi.org/10.1007/s10597-008-9164-5

Reitmanova, S., \& Gustafson, D. L. (2008). “They can't understand it”: Maternity health and care needs of immigrant Muslim women in St. John's, Newfoundland. Mater- 
nal and Child Health Journal, 12, 101-111. http://dx.doi.org/10.1007/s10995-0070213-4

Sarfraz, A., \& Castle, D. (2002). A Muslim suicide. Australian Psychiatry, 10, 48-50. http://dx.doi.org/10.1046/j.1440-1665.2002.00392.x

Shea, M., \& Yeh, C. J. (2008). Asian American students' cultural values, stigma, and relational self-construal: Correlates and attitudes toward professional help seeking. Journal of Mental Health Counseling, 30, 157-172.hea, M. and Yeh, C. J. 2008. Asian American students' cultural values, stigma, and relational self-construal: Correlates and attitudes toward professional help seeking. Journal of Mental Health Counseling, 30: 157-172.

Sue, D., \& Sue, S. (1972). Ethnic minorities: Resistance to being researched. Professional Psychology, 2, 11-17.

Toporek, R., Lewis, J., \& Crethar, H. (2009). Promoting systemic change through the ACA advocacy competencies. Journal of Counseling and Development, 87, 260268. http://dx.doi.org/10.1002/j.1556-6678.2009.tb00105.x

Townes, D. L., Chavez-Korell, S., \& Cunningham, N. J. (2009). Reexamining the relationship between racial identity, cultural mistrust, help-seeking attitudes, and preference for a Black counselor. Journal of Counseling Psychology, 56, 330-336. http://dx.doi.org/10.1037/a0015449

Trickett, E., \& Jones, C. (2007). Adolescent culture brokering and family functioning: A study of families from Vietnam. Cultural Diversity and Ethnic Minority Psychology, 2, 143-150. http://dx.doi.org/10.1037/1099-9809.13.2.143

Vogel, D., Wade, N., \& Hackler, A. (2007). Perceived public stigma and the willingness to seek counseling: The mediating roles of self-stigma and attitudes toward counseling. Journal of Counseling Psychology, 54, 40-50. http://dx.doi.org/10.1037/00220167.54.1.40

Zine, J. (2001). Muslim youth in Canadian schools: Education and the politics of religious identity. Anthropology and Education Quarterly, 32, 399-442. http://dx.doi. org/10.1525/aeq.2001.32.4.399 